\title{
Satisfação no Namoro e Bem-Estar Subjetivo: Associações com a Conjugalidade dos Pais ${ }^{12}$
}

\author{
Fabio Scorsolini-Comin ${ }^{3}$ \\ Universidade Federal do Triângulo Mineiro \\ Anne Marie Germaine Victorine Fontaine \\ Universidade do Porto \\ Manoel Antônio dos Santos \\ Universidade de São Paulo
}

\begin{abstract}
RESUMO - Este estudo investigou as relações existentes entre uma medida da conjugalidade dos pais (PCP) percebida por filhos solteiros que namoram e medidas do bem-estar subjetivo e da satisfação em relacionamentos amorosos desses jovens. Participaram deste estudo 140 pessoas solteiras (idade média $=21$ anos; tempo de namoro $=3$ anos). Os seguintes instrumentos foram utilizados: Escala de Bem-estar Subjetivo, Questionário de Conjugalidade dos Pais e Escala Fatorial de Satisfação com o Relacionamento de Casal. As correlações apontaram que a PCP não está correlacionada com as demais variáveis. A satisfação no namoro não está associada ao modo como o jovem percebe a conjugalidade de seus pais, contrariando a tese de que os relacionamentos afetivos seriam influenciados pelas experiências na família de origem.
\end{abstract}

Palavras-chave: relações conjugais, relações familiares, namoro, bem-estar subjetivo, satisfação conjugal

\section{Dating Satisfaction and Subjective Well-Being: Associations with Parental Marital Relationship}

\begin{abstract}
This study examined the association between a measure of parental marital relationship (PCP, in Portuguese) perceived by unmarried children who date and a measure of satisfaction and subjective well-being in romantic relationships of these young adults. In this study 140 unmarried subjects participated (mean age $=21$ years; dating $=3$ years). The following instruments were used: Scale of Subjective Well-being Parents' Conjugality Questionnaire and Factorial Scale of Satisfaction in Couple Relationships. Correlations indicated that PCP is not related to the other variables in this study. Thus, the satisfaction in dating is unrelated to how young adults perceive the marital relationship of their parents, refuting the thesis that affective relationships are influenced by the experiences in the family of origin.
\end{abstract}

Keywords: marital relations, family relations, dating, subjective well-being, marital satisfaction

$\mathrm{Na}$ Psicologia, muitos estudos têm investigado de que modo a família de origem pode estar relacionada ao desenvolvimento dos filhos na idade adulta (David, Gelberg, \& Suchman, 2012; Lau, Beilby, Byrnes, \& Hennessey, 2012; Vieira, Ávila, \& Matos, 2012). No que tange ao desenvolvimento afetivo dos filhos, a relação estabelecida

1 Artigo derivado da tese do primeiro autor, intitulada: "Família, sujeito composto: conjugalidade dos pais e sua relação com o bem-estar subjetivo e a satisfação nos relacionamentos amorosos dos filhos", defendida junto ao Programa de Pós-graduação em Psicologia da Faculdade de Filosofia, Ciências e Letras de Ribeirão Preto da Universidade de São Paulo, em 2012.

Outros trabalhos derivados da tese e já publicados: Scorsolini-Comin, Fontaine, Barroso \& Santos (2015); Scorsolini-Comin, Fontaine, Barroso \& Santos (2016); Scorsolini-Comin, Fontaine, \& Santos (2015).

2 Apoio: Programa Santander de Bolsas de Mobilidade Internacional e Coordenação de Aperfeiçoamento de Pessoal de Nível Superior (CAPES).

3 Endereço para correspondência: Programa de Pós-graduação em Psicologia da Universidade Federal do Triângulo Mineiro. Rua Conde de Prados, 155, Abadia, Uberaba-MG, CEP: 38025-260. E-mail: fabioscorsolini@gmail.com seria com o modo como os pais organizam e expressam sua conjugalidade e como os filhos percebem a afetividade do casal parental, que se torna uma das principais referências em termos de relacionamento amoroso (Willoughby, Carroll, Vitas, \& Hill, 2012).

Em outros estudos, investiga-se de que modo as primeiras relações, estabelecidas na infância, poderiam estar associadas ao modo como o adulto desenvolveria seus relacionamentos amorosos. Nessa vertente, modelos de apego inseguros na infância poderiam dar origem a esse mesmo padrão de expressão dos filhos na idade adulta, ao passo que modos mais seguros na infância aumentariam a probabilidade de que os filhos estabelecessem relacionamentos seguros no futuro (Bowlby, 1969/1990; Hare, Miga, \& Allen, 2009).

Para algumas abordagens, entre elas a psicanalítica, a conjugalidade dos pais exerceria forte influência na conjugalidade dos filhos, funcionando como uma baliza do que viria a ser um relacionamento íntimo entre duas pessoas ou também do que seria um casamento, haja vista que o primeiro casal com que o filho tem contato é, na maioria das vezes, aquele formado pelos próprios pais (Benghozi, 2010; Féres-Carneiro, Ziviani, \& Magalhães, 2007). É a 
partir da percepção dos filhos sobre a conjugalidade dos pais que esses jovens poderiam construir suas próprias noções acerca do casamento ou do relacionamento amoroso de casal (Scorsolini-Comin, Fontaine, \& Santos, 2015). No entanto, deve-se reconhecer que outras variáveis podem estar associadas ao estabelecimento de relacionamentos amorosos na vida adulta, como o bem-estar subjetivo (ScorsoliniComin \& Santos, 2012; Woyciekoski, Natividade, \& Hutz, 2014), possibilitando diversas vivências que tanto reeditem semelhanças com o casamento dos pais como promovam novas formas de vinculação, até mesmo escamoteando as experiências e recordações da infância consideradas traumáticas ou que não correspondam aos ideias de relacionamento perseguidos na vida adulta (Benghozi, 2010).

As primeiras relações amorosas estabelecidas pelos filhos, ainda durante a adolescência, são conhecidas por seus diferentes graus de intimidade e perenidade. $\mathrm{Na}$ contemporaneidade, observa-se uma pluralidade de definições e delimitações semânticas para a compreensão das diversas possibilidades de relacionamento. Para além do casamento e do namoro, emergem categorias como "ficar", "pegar", ter "namorido", apenas para mencionar as mais comuns. Embora algumas dessas nomenclaturas estejam asssociadas a relações passageiras e sem maior compromisso, que podem envolver ou não a prática sexual, o namoro é considerado uma modalidade de relacionamento mais estável ao longo do tempo, caracterizado pelo envolvimento afetivo dos parceiros, pelo grau de comprometimento estabelecido, pela menor liberdade conferida pelos parceiros e também pela construção de expectativas em relação ao casamento (Fonseca \& Duarte, 2014). Já os "namoridos" envolvem frequentemente a coabitação e a divisão de tarefas, em um arranjo mais próximo do casamento, embora não haja compromissos com a durabilidade e com a geração de descendentes (Duarte \& Rocha-Coutinho, 2011).

A partir dessa gama de delimitações possíveis dos relacionamentos amorosos na contemporaneidade, abrese a também complexa tarefa de mensurar a satisfação nos relacionamentos de casal. Embora a literatura aponte para um predomínio de estudos no âmbito do casamento (Féres-Carneiro, 1998; Scorsolini-Comin \& Santos, 2012; Uecker, 2012), cada vez mais estudos exploram a categoria namoro, notadamente pelo prisma da promoção da saúde, dos comportamentos sexuais e da violência nos relacionamentos íntimos (Levandowski, \& Schmidt, 2010; Murta, Santos, Martins, \& Oliveira, 2013; Oliveira, Gomes, Marques, \& Thiengo, 2007).

As intensas transformações operadas nas sociedades modernas tendem a fazer com que a experiência dos adultos seja considerada, pela nova geração, inadequada do ponto de vista de oferecer modelos que possam organizar e orientar formas de sociabilidade, levando os jovens a buscar referência não apenas nos pais, mas também em seu grupo de pares (Romanelli, 1995). No entanto, a influência da família de origem, principalmente do casal parental, ainda constitui um modelo a ser considerado e igualmente investigado. $\mathrm{Na}$ contemporaneidade, destaca-se que o namoro não apresenta mais um vínculo obrigatório com o casamento, como se dava anteriormente, por exemplo, no início do século XX. A noção de fidelidade pode ser questionada e a busca por um parceiro ou parceira ideal, com vistas a um relacionamento conjugal, também não é mais um balizador do que vem a ser um namoro (Eastwick, Finkel, \& Eagly, 2011; FéresCarneiro et al., 2007). Mesmo em meio a esse cenário de intensas mudanças, o namoro ainda persevera como uma modalidade de relacionamento anterior à conjugalidade, embora elementos conjugais típicos possam estar cada vez mais presentes nesses arranjos (Bertoldo \& Barbará, 2006; Fonseca \& Duarte, 2014; Oliveira et al., 2007).

A partir do exposto, o objetivo deste estudo foi investigar as relações existentes entre a medida da conjugalidade dos pais, tal como percebida por filhos solteiros e que namoram, e as medidas do bem-estar subjetivo e da satisfação em relacionamentos amorosos apresentados por esses filhos. As hipóteses delineadas a partir da literatura científica da área foram: (H1) A medida da percepção que os filhos têm acerca do relacionamento conjugal de seus pais está positivamente correlacionada à medida da percepção acerca de seus próprios relacionamentos (namoro); (H2) A medida da percepção que os filhos têm acerca de seus namoros está positivamente correlacionada com a medida de seus níveis de bem-estar subjetivo; (H3) A medida do bem-estar subjetivo dos jovens que namoram está correlacionada com a medida da satisfação global percebida no relacionamento conjugal dos pais.

\section{Método}

\section{Tipo de Estudo}

Trata-se de um estudo descritivo e correlacional, de corte transversal e cunho exploratório, apoiado em delineamento quantitativo de análise e interpretação dos dados.

\section{Participantes}

O estudo contou com uma amostra de pessoas de ambos os sexos, que se definem como heterossexuais, engajadas em namoros estáveis havia no mínimo dois anos, que tivessem entre 18 e 30 anos e com pais casados (legalmente ou em união estável) em primeiras núpcias. A delimitação de, no mínimo, dois anos de relacionamento foi adotada com vistas a recrutar participantes em namoros que pudessem ser considerados mais estáveis e com maior possibilidade de envolver uma convivência mais consistente. Os participantes não poderiam morar com os parceiros (coabitação), estar em processo de separação nem ter interrompido o namoro nos últimos dois anos. A inclusão de pessoas com pais casados deveu-se ao fato de que se pretendeu controlar o eventual efeito da situação conjugal na percepção dos filhos acerca do relacionamento conjugal (Ziviani, Féres-Carneiro, \& Magalhães, 2006).

Os participantes foram localizados em uma cidade de porte médio do interior do estado de São Paulo. A amostra foi do tipo não probabilística, composta por critérios de conveniência, totalizando 140 participantes, com média de idade de 21,99( $\pm 4,24)$, que namoravam havia 3,41( \pm 2,18 ) anos. Dos respondentes, $75 \%$ eram mulheres. No que 
Tabela 1. Caracterização Sociodemográfica da Amostra $(n=140)$

\begin{tabular}{|c|c|c|}
\hline Variáveis & n $(\%)$ & Média (DP) \\
\hline \multicolumn{3}{|l|}{ Sexo } \\
\hline Masculino & $35(25)$ & \\
\hline Feminino & $105(75)$ & \\
\hline Idade (em anos) & & $21,99(4,24)$ \\
\hline Renda familiar (em reais) & & $4.552,66(3.705,16)$ \\
\hline \multicolumn{3}{|l|}{ Classificação socioeconômica } \\
\hline Classe A & $38(27,14)$ & \\
\hline Classe B & $72(51,42)$ & \\
\hline Classe C & $30(21,42)$ & \\
\hline \multicolumn{3}{|l|}{ Grau de instrução } \\
\hline Ensino Médio Completo & $9(6,42)$ & \\
\hline Ensino Superior Incompleto & $110(78,57)$ & \\
\hline Ensino Superior Completo & $21(15)$ & \\
\hline \multicolumn{3}{|l|}{ Profissão/Ocupação } \\
\hline Estudante & $73(62,39)$ & \\
\hline Professor / Ensino Fundamental & $11(9,40)$ & \\
\hline Psicólogo & $9(7,69)$ & \\
\hline Auxiliar administrativo & $6(5,12)$ & \\
\hline Outras & $18(15,38)$ & \\
\hline Tempo de namoro (em anos) & & $3,41(2,18)$ \\
\hline Grau de satisfação no namoro & & $4,30(0,67)$ \\
\hline Nem um pouco & - & \\
\hline Um pouco & $2(1,42)$ & \\
\hline Moderadamente satisfatório & $11(7,85)$ & \\
\hline Bastante satisfatório & $70(50)$ & \\
\hline Extremamente satisfatório & $57(40,71)$ & \\
\hline \multicolumn{3}{|l|}{ Reside com os pais } \\
\hline Sim & $91(65)$ & \\
\hline Não & $49(35)$ & \\
\hline \multicolumn{3}{|l|}{ Idade dos pais (em anos) } \\
\hline Pais & & $51,90(6,47)$ \\
\hline Mães & & $49,27(5,77)$ \\
\hline $\begin{array}{l}\text { Tempo de casamento dos pais } \\
\text { (em anos) }\end{array}$ & & $26,07(4,99)$ \\
\hline
\end{tabular}

concerne ao grau de instrução, 78,57\% tinham formação superior incompleta ou em andamento, sendo que $62,39 \%$ eram estudantes. Dos respondentes, $91 \%$ residiam com os pais que, por sua vez, estavam casados havia $26,07( \pm 4,99)$ anos. Esses e os demais dados foram agrupados na Tabela 1.

\section{Instrumentos}

Questionário de Identificação do Participante. Questionário desenvolvido com o objetivo de fornecer dados gerais do participante, como idade, sexo, grau de instrução, atividade profissional, renda familiar, tempo de duração do relacionamento e se tem filhos ou não.

Classificação socioeconômica. O critério Abipeme (2008) é uma escala de classificação socioeconômica em que se atribuem pesos a um conjunto de itens de conforto doméstico, além do nível de escolaridade do chefe de família.

Escala de Bem-estar Subjetivo (EBES; Albuquerque \& Tróccoli, 2004). Trata-se de um instrumento inspirado em escalas extraídas da literatura internacional. A análise fatorial dos componentes principais e a análise fatorial (extração dos eixos principais - PAF e rotação oblimin) revelaram três fatores: afeto positivo (AP; 21 itens), afeto negativo (AN; 26 itens) e satisfação-insatisfação com a vida (SV; 15 itens). O instrumento é composto por duas partes com subescalas. A primeira parte agrupa as subescalas dos afetos positivos e negativos; e a segunda, a satisfação com a vida. Na primeira parte, os itens variam do número 1 ao 47 e descrevem afetos positivos e negativos, devendo o sujeito responder como tem se sentido ultimamente em uma escala tipo Likert, na qual 1 significa nem um pouco e 5, extremamente. Na segunda parte, os itens vão do número 48 ao 62 e descrevem julgamentos relativos à avaliação de satisfação ou insatisfação com a vida, devendo ser respondidos em uma escala tipo Likert, na qual 1 significa discordo plenamente e 5, concordo plenamente.

Questionário de Conjugalidade dos Pais (QCP; FéresCarneiro et al., 2007). A versão do QCP aplicada neste estudo é constituída por 56 itens, a serem respondidos em escala tipo Likert de cinco pontos, sendo que nunca corresponde a 1 e sempre corresponde a 5 . O instrumento permite que se utilizem as características psicométricas que sugerem a unidimensionalidade da escala de avaliação do QCP, dirigida ao construto maior: a conjugalidade dos pais percebida pelos filhos (Ziviani, Féres-Carneiro, \& Magalhães, 2011).

Escala Fatorial de Satisfação com o Relacionamento de Casal (EFS-RC; Wachelke, Andrade, Souza, \& Cruz, 2007). Instrumento autoadministrado breve, desenvolvido e validado no contexto brasileiro, composto por nove itens do tipo Likert. É subdividida em duas dimensões de avaliação de esferas específicas do relacionamento de casal: satisfação com a atração física e sexualidade (SAFS) e satisfação em relação às afinidades de interesses e comportamentos (SAIC) entre companheiros de relação.

Satisfação global com o relacionamento conjugal (SR). Trata-se de uma medida unidimensional, incluída no Questionário de Identificação do Participante, disposta em uma escala tipo Likert que varia de 1 (nem um pouco satisfatório) a 5 (extremamente satisfatório).

\section{Procedimento}

Coleta de dados. Os participantes foram contatados por meio do procedimento conhecido como bola de neve, em que novos sujeitos foram indicados pelos próprios respondentes que haviam sido contatados previamente pelo pesquisador. A aplicação dos instrumentos foi realizada de modo coletivo (em salas de aulas de duas universidades públicas) e também individualmente (nas residências dos voluntários), no caso de participantes localizados fora do contexto universitário. Os voluntários que concordassem em participar e que se enquadrassem nos critérios de inclusão, liam e assinavam o Termo de Consentimento Livre e Esclarecido e recebiam os cadernos contendo os instrumentos a serem respondidos. Esse processo durava, em média, 40 minutos. 
Análise dos dados. Após aplicação dos instrumentos, foi montado um banco de dados no Software SPSS for Windows versão 17.0. Primeiramente, foram feitas as análises descritivas para caracterização da amostra. Nessas análises, consideraram-se as médias, medianas, desvios-padrão e porcentagens. Concluído esse processo, foi aplicado o teste de normalidade Kolmogorov-Smirnov e a análise de resíduos. Como os dados não mostraram seguir distribuição normal, foi empregada estatística não-paramétrica para análise de correlações. Foram calculadas as correlações entre as medidas das variáveis contínuas dos fatores dos instrumentos apresentados, a partir do coeficiente de Spearman. A força da grandeza do coeficiente de correlação entre as variáveis foi avaliada conforme procedimento proposto por Ajzen e Fishbein (1998), que consideram os valores de correlação próximos de 0,30 satisfatórios, entre 0,30 e 0,50 como de moderada magnitude e acima de 0,50 de forte magnitude. Resultados abaixo de 0,30 são de pouco valor para a prática, mesmo que estatisticamente significantes. A escolha de tal classificação é justificada devido ao fato de ser uma investigação de medidas de construtos subjetivos (bemestar subjetivo, conjugalidade dos pais, satisfação em relacionamento de casal) que não podem ser observados diretamente pelo pesquisador. O nível de significância adotado no exame das correlações foi $p \leq 0,05$. Com os dados quantitativos, realizou-se uma análise correlacional, discutindo-se as implicações dessas associações em uma perspectiva psicossocial de investigação.

Tabela 2. Correlações e Respectivos Valores de $p$ Entre os Fatores de Bem-estar Subjetivo, Satisfação em Relacionamento de Casal e Percepção dos Filhos Sobre a Conjugalidade dos Pais em Pessoas Solteiras e que Namoram $(n=140)$

\begin{tabular}{lccccccc}
\hline & AP & NA & SV & SAFS & SAIC & PCP & SR \\
\hline AP & - & $-0,44^{* *}$ & $-0,03$ & 0,10 & $0,18^{*}$ & 0,14 & $0,19^{*}$ \\
& & 0,000 & 0,682 & 0,200 & 0,020 & 0,090 & 0,010 \\
AN & & - & $-0,09$ & $-0,05$ & 0,04 & $-0,09$ & $-0,26^{* *}$ \\
& & & 0,280 & 0,490 & 0,560 & 0,290 & 0,000 \\
SV & & - & 0,01 & 0,09 & 0,03 & $0,18^{*}$ \\
& & & & 0,900 & 0,240 & 0,660 & 0,030 \\
SAFS & & & - & $0,24^{* *}$ & 0,15 & $0,38^{* *}$ \\
& & & & & 0,000 & 0,060 & 0,000 \\
SAIC & & & & - & $-0,00$ & 0,15 \\
& & & & & & 0,930 & 0,060 \\
PCP & & & & & - & 0,10 \\
& & & & & & 0,210 \\
SR & & & & & & & - \\
\hline
\end{tabular}

Notas. $* \mathrm{p} \leq 0,05 ; * * \mathrm{p} \leq 0,01 ; \mathrm{AP}=$ afetos positivos; $\mathrm{AN}=$ afetos negativos; $\mathrm{SV}=$ satisfação com a vida; SAFS = satisfação com a atração física e sexualidade; SAIC = satisfação com a afinidade de interesses e comportamentos; $\mathrm{PCP}=$ percepção dos filhos sobre a conjugalidade dos pais; $\mathrm{SR}=$ grau de satisfação com o relacionamento.

\section{Considerações Éticas}

Este estudo foi aprovado pelo Comitê de Ética em Pesquisa da Faculdade de Filosofia, Ciências e Letras de Ribeirão Preto da Universidade de São Paulo (Processo 439/2009)

\section{Resultados}

Entre os resultados encontrados, destaca-se o índice de satisfação no relacionamento (SR) no namoro, cuja média foi 4,30. Em uma escala que varia de 1 (menos satisfeito) a 5 (mais satisfeito), pode-se considerar que a maior parte da amostra avalia de modo satisfatório o seu namoro. Todas as correlações encontradas entre os construtos investigados foram sistematizadas na Tabela 2.

Em termos dos fatores do bem-estar subjetivo (BES), os afetos positivos (AP) estão significativamente correlacionados com os afetos negativos (AN; rho $=-0,44 ; p<0,001$ ). Não houve correlação com a satisfação com a vida (SV; rho $=$ -0,03; $p=0,682$ ). Esse achado está em discordância em relação ao que foi encontrado no estudo de Albuquerque e Tróccoli (2004), que apontou correlações significativas entre os três fatores, utilizando uma amostra composta por pessoas casadas e solteiras. A direção negativa entre os AP e a SV também foi oposta aos achados do estudo de Scorsolini-Comin e Santos (2012), que apontou que esses dois fatores possuiriam características semelhantes e deveriam ser positivamente associados: quanto mais afetos positivos, mais a pessoa estaria satisfeita com a vida. Os AP correlacionaram-se significativamente com a SAIC (rho $=$ $0,18 ; p=0,020)$, o que também se observa em relação à SR no namoro $(r h o=0,19 ; p=0,010)$. Pessoas com maiores índices de afetos positivos tenderiam a expressar maior satisfação com o namoro e o relacionamento atual.

Os AN não se correlacionaram com os fatores da EFS$\mathrm{RC}$, mas apresentaram correlação significativa e moderada com a SR no namoro ( $r h o=-0,26 ; p=0,002)$. Como é uma correlação negativa, quanto maior o nível de afetos negativos, menor a satisfação no namoro. $\mathrm{O}$ fator $\mathrm{SV}$ esteve significativa e fracamente correlacionado com o grau de satisfação no namoro ( $r h o=0,18 ; p=0,030$ ).

No que concerne ao domínio geral da SR, há que se destacar que pessoas que fazem um julgamento positivo acerca da vida, ou seja, que expressam alto índice de satisfação com a vida, também tendem a estar mais satisfeitas com seus namoros. Outro dado a ser destacado é que nenhum dos fatores do BES mostrou-se correlacionado com a percepção dos filhos sobre a conjugalidade dos pais (PCP). Em relação aos fatores da EFS-RC, a SAFS apresentou-se significativa e moderadamente correlacionada com o grau de satisfação no namoro ( $r h o=0,38 ; p<0,001)$. Tanto SAFS como SAIC não se mostraram correlacionados com a PCP.

Ao examinar as hipóteses do estudo à luz dos resultados obtidos, pode-se afirmar que a H1 não pôde ser aceita, uma vez que a percepção sobre a conjugalidade dos pais não se correlacionou significativamente com quaisquer dos fatores, tanto da EFS-RC quanto do inquérito sobre a satisfação no namoro. A segunda hipótese não foi rejeitada, uma vez que a SAIC correlacionou-se com os AP ( $r h o=0,18 ; p=0,029)$, assim como a SR com os três fatores do BES: $\mathrm{AP}(r h o=0,19$; $p=0,019)$, AN (rho $=-0,26 ; p=0,002)$ e SV $(r h o=0,18$; $p=0,030)$. Embora sejam significativas, há que se destacar que se trata de correlações consideradas fracas (Ajzen \& Fishbein, 1998), indicando a necessidade de parcimônia na compreensão dessa associação. A terceira hipótese foi rejeitada nessa amostra, uma vez que a percepção dos filhos sobre a conjugalidade dos pais não se correlacionou com 
quaisquer dos fatores do BES. Desse modo, nessa amostra de pessoas solteiras que namoram, os componentes individuais do bem-estar subjetivo não podem ser associados à percepção dos respondentes acerca do relacionamento conjugal dos pais. A PCP estaria, portanto, associada a outros fatores que não o BES.

\section{Discussão}

Nos jovens investigados, os AP estão correlacionados satisfatoriamente com os $\mathrm{AN}$, mas a $\mathrm{SV}$, terceiro fator do $\mathrm{BES}$, não se correlacionou com os $\mathrm{AP}$ e $\mathrm{AN}$, o que diverge dos resultados obtidos nos estudos de Albuquerque e Tróccoli (2004) e de Scorsolini-Comin e Santos (2012). No entanto, esses autores não trabalharam com uma amostra específica de solteiros nem com maioria de estudantes, como no caso do presente estudo, o que pode explicar a obtenção de resultados diferentes. Em termos das medidas de satisfação em relacionamento de casal, na presente investigação, a SAFS mostrou-se significativa e fracamente correlacionada com a SAIC, fato esperado por se tratar de dimensões de um mesmo construto.

Estudos que visam a estabelecer relações entre o bemestar e os relacionamentos amorosos discorrem sobre o fato de as pessoas casadas desfrutarem de maior nível de bemestar ou de satisfação com a vida (Lyubomirsky, King, \& Diener, 2005; Mastekaasa, 1994). Embora algumas pesquisas apontem para o fato de que essa consideração possa ser expandida para outros relacionamentos amorosos (Berry \& Willingham, 1997), entre os quais enquadramos o namoro, não foram encontrados estudos que tenham analisado especificamente essa condição. Pesquisa de Woyciekoski et al. (2014), conduzida no contexto brasileiro, destacou que eventos de vida, como o término do namoro, podem até mesmo potencializar o aumento do bem-estar justamente por permitirem um novo sentido de vida pelo desligamento do sujeito de uma relação que não era considerada satisfatória. Assim, um evento frequentemente considerado negativo ou estressor poderia ter uma repercussão positiva para o indivíduo, a depender da qualidade dessa relação.

Para Wachelke et al. (2007), a escala de satisfação em relacionamento de casal é mais consistente quando aplicada em amostras de pessoas que tenham um relacionamento mais estável, como no caso do casamento. O namoro, ainda que possa ser considerado uma modalidade de relacionamento estável, pode guardar diferenças significativas em relação ao casamento, como coabitação, divisão das tarefas e responsabilidades, assunção de papéis adultos, bem como da conciliação entre família e trabalho, que são aspectos frequentemente investigados nos contextos conjugais (Biehle \& Mickelson, 2012; Hostetler, Desrochers, Kopko, \& Moen, 2012).

Um ponto a ser considerado é que a definição do que é um namoro vem sofrendo diversos ajustes em relação à pluralidade de formas de se experienciar um relacionamento amoroso na contemporaneidade, o que tem permitido questionar cada vez mais aspectos como duração dos relacionamentos, fidelidade, liberdade, coabitação e expectativas em relação ao casamento e à parentalidade
(Duarte \& Rocha-Coutinho, 2011; Fonseca \& Duarte, 2014). No entanto, a definição do que é um casamento parece ser mais constante quando analisamos culturas distintas (Mastekaasa, 1994), constituindo assim um fenômeno mais universal, ainda que diferentes valores e pressupostos possam orientar a definição do que seria a união conjugal. Esse caráter mais universal, tradicional ou cristalizado do fenômeno casamento pode justificar, inclusive, sua maior incidência nas pesquisas, inclusive em investigações transculturais, interessadas em traçar paralelos entre diferentes culturas no que tange a aspectos como costumes, valores, tradições, aliança conjugal e exercício da parentalidade.

Apesar de a PCP ser elevada na amostra, esse índice não se correlacionou significativamente com as demais variáveis do estudo. Assim, para solteiros que namoram, a percepção sobre o casamento de seus pais não se mostrou associada a fatores tais como AP, AN, SV e SR. Em pesquisa conduzida com pessoas casadas (Scorsolini-Comin, Fontaine, Barroso, \& Santos, 2015), a PCP esteve associada a uma das dimensões da SR, a SAIC (interesses e comportamentos). Desse modo, a PCP pode se apresentar de modo distinto em indivíduos solteiros e casados.

Pode-se aventar que pessoas casadas, por vivenciarem uma experiência mais próxima da conjugalidade do que em um namoro, tal como mensurado neste estudo (sem coabitação), reconheceriam que a percepção do casamento de outrem é, minimamente, ativada pela experiência do próprio casamento e das experiências acumuladas ao longo da vida. Quando se busca compreender o modo como os relacionamentos amorosos se apresentam na vida adulta e sua possível associação com aspectos observados na família de origem ou no casal parental que serve como modelo para essas relações, deve-se abrir à possibilidade de uma leitura que tanto considere a repetição de modelos como a recusa dos casais em seguir passos semelhantes aos dos pais. Em uma leitura psicanalítica, nem sempre esse processo é consciente, mas o que pode ser evidenciado é que há uma abertura possível para a recriação ou para a remalhagem dos vínculos (Benghozi, 2010).

No caso dos solteiros que namoram, pelos dados do presente estudo, o modo como percebem o relacionamento dos pais parece não estar associado ao modo como avaliam o próprio namoro, o que nos permite uma leitura menos determinista e que se abre à remalhagem como um trabalho do indivíduo a partir dos diversos relacionamentos interpessoais estabelecidos ao longo da vida, inclusive do namoro. Embora os dados do presente estudo e o delineamento estatístico proposto não nos permitam afirmar que o namoro contribua para que o indivíduo remalhe vínculos iniciais considerados negativos, é lícito ponderar que há uma limitação no modo como os conteúdos psíquicos e as imagens sobre o relacionamento amoroso são transmitidos no núcleo familiar. Isso abre espaço para que outras variáveis relacionadas sejam também consideradas para apreender, de fato, o que é acionado pelo sujeito na estruturação de suas relações de casal na vida adulta. Entre as várias possibilidades de compreensão que emergem, aventa-se a hipótese de que os grupos de pares podem ter uma influência maior do que os membros da família de origem. Essa conjectura deve ser analisada em estudos vindouros. 
Os participantes, ao avaliarem seus namoros, mostram que tais julgamentos estão fracamente associados aos seus níveis de $\mathrm{AP}(r h o=0,19 ; p=0,019), \mathrm{AN}$ ( $r h o=-0,26 ; p=$ $0,002)$ e de SV (rho $=0,18 ; p=0,030)$. Podemos afirmar, amparados nesse resultado, que, quanto maior o nível de BES do sujeito, maior a possibilidade de que ele faça uma leitura igualmente positiva acerca do próprio namoro. Essa avaliação unidimensional também se correlacionou significativa e moderadamente com a SAFS ( $r h o=0,38 ; p<0,001)$.

Portanto, a SR se correlacionou de modo significativo com a SAFS, os AP e os AN. Esses dados remetem ao estudo de Chaves (2010) sobre a percepção de jovens contemporâneos sobre os relacionamentos amorosos. A autora destaca, como característica da geração investigada, a ênfase dada ao aqui e agora, ou a um "presente contínuo", em referência a uma expressão de Bauman (1998). Tal característica faria com que o longo prazo perdesse o sentido e contribuísse para que os compromissos duradouros fossem vistos como aprisionamentos. Esses apontamentos também foram trazidos no estudo de Duarte e Rocha-Coutinho (2011) com os chamados casais de "namoridos", marcados pela busca de uma satisfação pessoal instantânea nos relacionamentos amorosos, sem compromisso com a durabilidade da aliança. $\mathrm{O}$ fato de a SR estar vinculada mais ao comportamento sexual e à redução de emoções consideradas negativas pode sugerir o aprisionamento desses jovens às imagens fortemente evocadas de efemeridade e de vínculos metaforizados como "líquidos", ainda em referência ao pensamento de Bauman. Assim, os relacionamentos seriam valorizados à medida que fossem satisfatórios, notadamente no que se refere à gratificação sexual. Destaca-se, assim, a busca pela novidade, valorização do bom desempenho sexual e disponibilidade em oferecer prazer ao outro.

$\mathrm{Na}$ literatura científica, poucos estudos investigam as diferenças entre casais que namoram e aqueles casados consensualmente, também em decorrência da dificuldade em se definir o que é um namoro atualmente e no que um casamento consensual difere dos demais arranjos afetivos (Duarte \& Rocha-Coutinho, 2011; Fonseca \& Duarte, 2014; Scorsolini-Comin et al., 2015). E isso é válido mesmo se pensarmos apenas nos arranjos considerados mais tradicionais, como os vínculos heterossexuais e monogâmicos. Féres-Carneiro et al. (2007) apresentam a proposta de conceber como conjugalidades contemporâneas outros arranjos, tais como os estabelecidos entre pessoas do mesmo sexo, o "ficar", noivado, namoro, recasamento, coabitação, relações virtuais e mesmo o denominado poliamor. Obviamente, torna-se inviável abarcar todas essas modalidades em um mesmo estudo, de modo que o mais exequível seria estabelecermos recortes, a fim de aprofundar a compreensão de determinados arranjos.

O critério de coabitação, por vezes, é utilizado para se delimitar um relacionamento dito sério de outra possibilidade de vinculação. A coabitação pode ser compreendida como uma forma de relacionamento conjugal não-tradicional (Féres-Carneiro et al., 2007; Osborne, Berger, \& Magnuson, 2012; Rhoades, Stanley, \& Markman, 2012), um estilo alternativo de vida ou um rito preliminar ao casamento (Fonseca \& Duarte, 2014), ou mesmo uma característica dos "namoridos" (Duarte \& Rocha-Coutinho, 2011). Tal complexidade é referida no estudo de Hsueh, Morrison e Doss (2009), que destacam que as principais tendências apontam para investigações que traçam as diferenças entre aqueles que namoram, coabitam e são casados em termos de variáveis como: acordo e desacordo no casal, violência, saúde mental, parentalidade e gênero, o que se distancia dos objetivos do presente estudo, que trata da satisfação e da conjugalidade. De qualquer modo, embora seja complexa a tarefa de definir e delimitar o que se compreende por casamento e namoro, há consenso na literatura de que se trata de grupos distintos, com concepções específicas sobre família, compromisso, responsabilidade e relacionamento amoroso.

\section{Considerações Finais}

Neste estudo, com amostra de jovens que namoram, não foram encontradas correlações fortes entre as variáveis investigadas. Houve apenas correlações moderadas entre SR e SAFS e entre AP e AN. Em relação a essas duas últimas variáveis, não houve discordância em termos do que já vinha sendo observado na literatura sobre o bem-estar subjetivo. Acerca das duas primeiras, trata-se de um resultado esperado. A correlação entre bem-estar subjetivo e satisfação no namoro foi fraca, de modo que não podemos afirmar categoricamente que estar satisfeito no namoro esteja associado ao fato de ter bons níveis de bem-estar, o que se distancia da literatura na área, que atesta que pessoas engajadas em relacionamentos amorosos apresentariam maiores níveis de bem-estar e de satisfação com a vida.

A principal variável do estudo, a PCP, não manteve associações significativas com quaisquer das demais variáveis, de modo que, a partir desta amostra, pode-se concluir que o modo como os jovens percebem o relacionamento conjugal dos pais em nada interfere em seus namoros. Isso pode ser compreendido pelo fato de que os relacionamentos observados nos grupos de pares podem ter uma influência maior do que aqueles da família de origem. Desse modo, em estudos futuros, poderiam ser considerados esses grupos, a fim de compreender de modo mais acurado o que esses jovens elegem como modelo para seus relacionamentos amorosos. Tal achado indica que, para além do casal parental, outros casais ou formas de envolvimento afetivo podem inspirar e balizar a construção da conjugalidade na fase adulta. No caso dos namoros, é preciso compreender com precisão como esses relacionamentos são construídos e com base em quais referenciais.

Entre as limitações do estudo, há que se considerar que a amostra, embora composta por critérios de conveniência e sem que o pesquisador tivesse qualquer conhecimento prévio dos participantes, estava predominantemente muito satisfeita no namoro. Metade dos entrevistados declarou-se bastante satisfeita no namoro e outros $40,71 \%$ extremamente satisfeitas, podendo-se afirmar que mais de $90 \%$ da amostra considerava-se satisfeita. Outras estratégias de composição da amostra poderiam ter sido empregadas a fim de diminuir o viés causado por essa característica dos jovens pesquisados. Outras variáveis poderiam também ser elencadas para uma compreensão mais ampla do fenômeno, como os eventos 
de vida e algum inquérito que permitisse investigar as expectativas quanto ao futuro.

Por fim, sugere-se a realização de mais estudos com jovens solteiros que namoram. Compreender o que esses jovens definem como namoro também tem se mostrado uma preocupação relevante, a fim de clarificar o que pode ser apreendido nessa modalidade de relacionamento, bem como as diversas transformações e reinvenções que se operam no contexto das relações amorosas e das configurações familiares. O que caracteriza esse relacionamento atualmente: duração do namoro, estabilidade, segurança emocional, fidelidade, amor, companheirismo? Quais os elementos destacados pelos jovens para a construção de seus namoros? $\mathrm{Na}$ contemporaneidade, no entanto, os limites entre as diferentes definições de relacionamento amoroso têm sido cada vez mais discutidos, de modo que o presente estudo configura-se como um exercício de conferir visibilidade aos relacionamentos estabelecidos antes do casamento, ainda que tal definição não seja uníssona e perene.

\section{Referências}

Ajzen, I., \& Fishbein, M. (1998). Understanding attitudes and predicting social behavior. New Jersey: Prentice-Hall.

Albuquerque, A. S., \& Tróccoli, B. T. (2004). Desenvolvimento de uma escala de bem-estar subjetivo. Psicologia: Teoria e Pesquisa, 20(2), 153-164. doi: 10.1590/S010237722004000200008

Associação Brasileira dos Institutos de Pesquisa de Mercado. (2008). Critério de classificação socioeconômica do Brasil (CCSEB). São Paulo: ABA, ANEP, ABIPEME.

Bauman, Z. (1998). O mal-estar da pós-modernidade (M. Gama, \& C. M. Gama, Trads.). Rio de Janeiro: Jorge Zahar.

Benghozi, P. (2010). Malhagem, filiação e afiliação - Psicanálise dos vínculos: Casal, família, grupo, instituição e campo social (E. D. Galery, Trad.). São Paulo: Vetor.

Berry, D. S., \& Willingham, J. K. (1997). Affective traits, responses to conflict, and satisfaction in romantic relationships. Journal of Research in Personality, 31, 564-576. doi: 10.1006/ jrpe.1997.2198

Bertoldo, R. B., \& Barbará, A. (2006). Representação social do namoro: A intimidade na visão dos jovens. Psico - USF, 11(2), 229-237.

Biehle, S. N., \& Mickelson, K. D. (2012). First-time parents' expectations about the division of childcare and play. Journal of Family Psychology, 26(1), 36-45.

Bowlby, J. (1990). Apego e perda: Apego - A natureza do vínculo (Á. Cabral, Trad.). São Paulo: Martins Fontes. (Original publicado em 1969)

Chaves, J. C. (2010). As percepções de jovens sobre os relacionamentos amorosos na atualidade. Psicologia em Revista, 16(1), 28-46.

David, D. H., Gelberg, L., \& Suchman, N. E. (2012). Implications of homelessness for parenting young children: A preliminary review from a developmental attachment perspective. Infant Mental Health Journal, 33(1), 1-9. doi: 10.1002/imhj.20333

Duarte, J. P., \& Rocha-Coutinho, M. L. (2011). "Namorido": Uma forma contemporânea de conjugalidade? Psicologia Clínica, 23(2), 117-135.
Eastwick, P. W., Finkel, E. J., \& Eagly, A. H. (2011). When and why do ideal partner preferences affect the process of initiating and maintaining romantic relationships?. Journal of Personality and Social Psychology, 101(5), 1012-1032. doi: 10.1037/ a0024062

Féres-Carneiro, T. (1998). Casamento contemporâneo: O difícil convívio da individualidade com a conjugalidade. Psicologia: Reflexão e Crítica, 11(2), 379-394.

Féres-Carneiro, T., Ziviani, C., \& Magalhães, A. S. (2007). Questionário sobre a conjugalidade dos pais como instrumento de avaliação. In T. Féres-Carneiro (Org.), Família e casal: Saúde, trabalho e modos de vinculação (pp. 251-268). São Paulo: Casa do Psicólogo.

Fonseca, S. R. A., \& Duarte, C. M. N. (2014). Do namoro ao casamento: Significados, expectativas, conflito e amor. Psicologia: Teoria e Pesquisa, 30(2), 135-143. doi: 10.1590/ S0102-37722014000200002

Hare, A. L., Miga, E. M., \& Allen, J. P. (2009). Intergenerational transmission of aggression in romantic relationships: The moderating role of attachment security. Journal of Family Psychology, 23(6), 808-818. doi: 10.1037/a0016740

Hostetler, A. J., Desrochers, S., Kopko, K., \& Moen, P. (2012). Marital and family satisfaction as a function of work-family demands and community resources: Individual and couple level analyses. Journal of Family Issues, 33(3), 316-340. doi: 10.1177/0192513X11413877

Hsueh, A. C., Morrison, K. R., \& Doss, B. D. (2009). Qualitative reports of problems in cohabiting relationships: Comparisons to married and dating relationships. Journal of Family Psychology, 23(2), 236-246. doi: 10.1037/a0015364

Lau, S. R., Beilby, J. M., Byrnes, M. L., \& Hennessey, N. W. (2012). Parenting styles and attachment in school-aged children who stutter. Journal of Communication Disorders, 45(2), 98-110. doi: 10.1016/j.jcomdis.2011.12.002

Levandowski, D. C., \& Schmidt, M. M. (2010). Oficina sobre sexualidade e namoro para pré-adolescentes. Paidéia (Ribeirão Preto), 20(47), 431-436.

Lyubomirsky, S., King, L., \& Diener, E. (2005). The benefits of frequent positive affect: Does happiness lead to success? Psychological Bulletin, 131, 803-855. doi: 10.1037/00332909.131.6.803

Mastekaasa, A. (1994). Marital status, distress, and well-being: An international comparison. Journal of Comparative Family Studies, 25, 183-205.

Murta, S. G., Santos, B. R. P., Martins, C. P. S., \& Oliveira, B. (2013). Prevenção primária à violência no namoro: Uma revisão de literatura. Contextos Clínicos, 6(2), 117-131.

Oliveira, D. C., Gomes, A. M. T., Marques, S. C., \& Thiengo, M. A. (2007). "Pegar", "ficar" e "namorar": Representações sociais de relacionamentos entre adolescentes. Revista Brasileira de Enfermagem, 60(5), 497-502. doi: 10.1590/ S0034-71672007000500003

Osborne, C., Berger, L. M., \& Magnuson, K. (2012). Family structure transitions and changes in maternal resources and well-being. Demography, 49(1), 23-47. doi: 10.1007/s13524011-0080-x

Rhoades, G. K., Stanley, S. M., \& Markman, H. J. (2012). A longitudinal investigation of commitment dynamics in cohabiting relationships. Journal of Family Issues, 33(3), 369-390. doi: 10.1177/0192513X11420940 
Romanelli, G. (1995). Autoridade e poder na família. In M. C. B. Carvalho (Org.), A família contemporânea em debate (pp. 73-88). São Paulo: EDUC/Cortez.

Scorsolini-Comin, F., Fontaine, A. M. G. V., Barroso, S. M., \& Santos, M. A. (2015). Relações entre conjugalidade dos pais, conjugalidade dos filhos e bem-estar subjetivo. Psico-USF, 20(3), 481-492. doi: 10.1590/1413-82712015200310

Scorsolini-Comin, F., Fontaine, A. M. G. V., Barroso, S. M., \& Santos, M. A. (2016). Fatores associados ao bem-estar subjetivo em pessoas casadas e solteiras. Estudos de Psicologia (Campinas), 33(2), 313-324. doi: http://dx.doi. org/10.1590/1982-02752016000200013

Scorsolini-Comin, F., Fontaine, A. M. G. V., \& Santos, M. A. (2015). Conjugalidade dos pais: Percepções de indivíduos casados e solteiros. Avaliação Psicológica, 14(2), 223-231. doi: 10.15689/ap.2015.1402.07

Scorsolini-Comin, F., \& Santos, M. A. (2012). Correlations between subjective well-being, dyadic adjustment and marital satisfaction in Brazilian married people. The Spanish Journal of Psychology, 15(1), 166-176. doi: 10.5209/rev_SJOP.2012. v15.n1.37304

Seligman, M. E. P. (2011). Florescer: Uma nova compreensão sobre a natureza da felicidade e do bem-estar (C. P. Lopes, Trad.). Rio de Janeiro: Objetiva.
Uecker, J. E. (2012). Marriage and mental health among young adults. Journal of Health and Social Behavior, 53(1), 67-83. doi: 10.1177/0022146511419206

Vieira, J. M., Ávila, M., \& Matos, P. M. (2012). Attachment and parenting: The mediating role of work-family balance in Portuguese parents of preschool children. Family Relations, 61(1), 31-50. doi: 10.1111/j.1741-3729.2011.00680.x

Wachelke, J. F. R., Andrade, A. L., Souza, A. M., \& Cruz, R. M. (2007). Estudo complementar da validade fatorial da escala fatorial de satisfação em relacionamento e predição de satisfação global com a relação. Psico - USF, 12(2), 221-225.

Willoughby, B. J., Carroll, J. S., Vitas, J. M., \& Hill, L. M. (2012). "When are you getting married?": The intergenerational transmission of attitudes regarding marital timing and marital importance. Journal of Family Issues, 33(2), 223-245. doi: 10.1177/0192513X11408695

Woyciekoski, C., Natividade, J. C., \& Hutz, C. S. (2014). As contribuições da personalidade e dos eventos de vida para o bem-estar subjetivo. Psicologia: Teoria e Pesquisa, 30(4), 401-409. doi: 10.1590/S0102-37722014000400005

Ziviani, C., Féres-Carneiro, T., \& Magalhães, A. S. (2011). Sons and daughters' perception of parents as a couple: Distinguishing characteristics of a measurement model. Psicologia: Reflexão e Crítica, 24(1), 28-39. doi: 10.1590/ S0102-79722011000100005

Recebido em 16.12.2013

Primeira decisão editorial em 11.04.2016

Versão final em 03.05.2016

Aceito em 12.08.2016 